\title{
THE INFLUENCE OF pH ON THE DETERIORATION OF VEGETABLE-TANNED LEATHER BY SULPHURIC ACID
}

\author{
By R. C. Bowker and E. L. Wallace
}

\section{AESTRACT}

Thirteen different lots of vegetable-tanned leather were prepared, treated with varying amounts of sulphuric acid, tested for tensile strength, and placed in storage for two years, after which strength tests were again made. The loss in strength on aging was used as a measure of the deterioration, and the results are presented in a series of graphs as a function of the initial $\mathrm{pH}$ of the leather. It is shown that all of the leathers started to deteriorate at or near $\mathrm{pH} 3$ regardless of the kind of vegetable-tanning material used, the degree of tannage, the amount of sulphuric acid added to the leather at the critical $\mathrm{pH}$, the aging conditions, and the $\mathrm{pH}$ of the original leather before being treated with acid. The hydrolysis of the leathers, as measured by determining the nitrogen extractable with cold water, also increased sharply near $\mathrm{pH} 3$. The results strongly indicate that vegetable-tanned leather will start to deteriorate at about this point whatever the combination of circumstances may be which causes it to have this critical value. Serious consideration of the value of a $\mathrm{pH}$ measurement for indicating the harmful acidity of leather is advocated, the limiting values for different leathers to be governed by the length of service expected and the conditions of use.

\section{CONTENTS}

I. Introduction

II. Materials and methods

III. Results and discussion

561

IV. Summary

565

\section{INTRODUCTION}

The determination of the acid content of leather has been a major research subject for many years. Since 1895 no less than 16 analytical methods have been proposed for directly determining this constituent of leather. The Proctor and Searle method, which involves ashing the leather with a substance capable of combining with sulphuric acid, is the chief one used in this country at the present time. In general, the recognized limitations of this method are: (1) The total acid present may not always be determined, (2) sulphur from any source present in the leather may be determined as acid, and (3) no indication is obtained relative to the presence of strong organic acids which may be harmful.

These limitations became of much greater importance as the development and increased use of sulphonated and sulphited leathermaking materials proceeded. In this connection sulphonated oils, sulphited vegetable tanning materials, sulphite cellulose extract, and synthetic tanning materials (sulphonated condensation products from coal-tar crudes) may be mentioned. The use of these materials and also certain finishing products which contain strong organic acids or salts of these acids has made increasingly doubtful the value, by itself, of any of the known direct analytical methods for indicating the true acidity of leather. 
The situation has logically led to an examination of $\mathrm{pH}$ methods for indicating the acidity of leather. Kohn and Crede ${ }^{1}$ suggested making $\mathrm{pH}$ measurements of water solutions in equilibrium with finely divided leather and plotting neutralization curves for a sufficient number of leather samples of known tannage and wearing quality so as to establish a permissible upper limit for acidity. They further stated that all good leather samples tested in this way showed an initial $\mathrm{pH}$ value of about 3 or only slightly below 3 . Since that time Pickard and Caunce, ${ }^{2}$ Bradley and Cohen, ${ }^{3}$ Innes, ${ }^{4}$ Atkins and Thompson, ${ }^{5}$ and Kubelka and Wolmarker, ${ }^{6}$ have devised methods which involve the measurement of the $\mathrm{pH}$ values of leather and water systems.

An investigation of the effects of sulphuric acid on different vegetable-tanned leathers during storage has been in progress at this bureau for some years, and a number of reports have been issued ${ }^{7}$ in which the deterioration of the leather measured by its loss in strength on aging, has been expressed as a function of the sulphuric acid present in the leather. As a part of this investigation $\mathrm{pH}$ measurements were made on all samples of leather before they were placed in storage. Data are now available for 13 different lots of vegetable-tanned leather, each treated with rarying amounts of sulphuric acid and aged for two years, for an expression of deterioration as a function of the $\mathrm{pH}$ of the leather. It is the purpose of this report to present this information as additional evidence of the substantial value of $\mathrm{pH}$ measurements for evaluating leather with respect to acidity.

\section{MATERIALS AND METHODS}

The leather used in this work consisted of lot Nos. 1 to 12 , inclusive, and lot No. 14. The method of preparing these leathers and the procedure followed in making aging tests have been adequately described in previous reports, ${ }^{8}$ which also contain the chemical analyses and aging test results for lots Nos. 1 to 11 , inclusive. No previous report has been made on lots Nos. 12 and 14, which were tanned with mangrove bark and sumac extracts, respectively. The chemical analyses of these two leathers are given in Table 1:

The A. L. C. A. methods were used for all analytical work on the leather excepting for the determination of the $\mathrm{pH}$ values and the amount of sulphuric acid added. The latter was checked by a modified wuensch method previously reported. ${ }^{9}$

The $\mathrm{pH}$ measurements were made in a water solution in equilibrium with finely divided leather, $4.9 \mathrm{~g}$ of dry leather being weighed into a beaker and $100 \mathrm{ml}$ distilled water added. The system was allowed to stand overnight in order to reach equilibrium conditions; that is until no further variation in the $\mathrm{pH}$ value was observed on longer contact of the leather with water solution, before making a reading.

1 The Actdity of Vegetnble Tanned Leather, J. Am. Lea. Chem. Assoc., vol. 18, p. 189, 1923.
2J. Int. Noc. Lea. Tr. Chem., vol. 8, p. 156, 1924.

3J. Int. Soc. LeH. Tr. Chem., vol. 8, p. 340, 1924.

J. Int. Sor. Ien. Tr. (hem., vol. 12, p. 256, 1928.

J. Int. Soc. Les. Tr. Chem., vol. 13, p. 300, 1920.

- Colleglum, p. 08, 1931.

1 J. Am. Len. (Chem. Assoc., vol. 23, p. 82, 1925; vol. 26, P. 444, 1931; vol. 26, p. 667, 1931; vol. 27, p. 81, 1932; vol. 27, ए. 155, 1932.

- See foninote 7 . 
Hydrogen electrodes of the Hildebrand type were used. A fresh electrode was used for making each $\mathrm{pH}$ measurement. This limitation on the use of the electrodes was necessary because of the poisoning effect of copper which was in the tanning extracts. The apparatus has been described in a previous report. ${ }^{10}$

TABLE 1.-Chemical analyses of leathers

[Results expressed in per cent, excepting for degree of tannage and pH values]

\begin{tabular}{|c|c|c|}
\hline Tanned with- & $\begin{array}{l}\text { Lot No. 12, } \\
\text { mangrove }\end{array}$ & $\begin{array}{l}\text { Lot No. 14, } \\
\text { sumac }\end{array}$ \\
\hline $\begin{array}{l}\text { Water solubles. } \\
\text { Hide substance } \\
\text { Grease (P. E. E.) } \\
\text { Moisture } \\
\text { Insoluble ash.... } \\
\text { Combined tannin }{ }^{1}-\ldots\end{array}$ & $\begin{array}{r}10.28 \\
48.42 \\
4.23 \\
9.70 \\
27.08 \\
27.29\end{array}$ & $\begin{array}{r}6.74 \\
49.68 \\
3.03 \\
7.49 \\
32.15 \\
32.91\end{array}$ \\
\hline Total & 100.00 & 100.00 \\
\hline $\begin{array}{l}\text { Degree of tannage }{ }^{2} \\
\text { Soluble tans. } \\
\text { Soluble nontans } \\
\text { Total ash } \\
\text { Acdd (P and } \mathrm{S} \text { ) } \\
\text { pH value }{ }^{3}\end{array}$ & \begin{tabular}{r|}
56.40 \\
8.02 \\
2.26 \\
.15 \\
.12 \\
5.19
\end{tabular} & $\begin{array}{r}66.50 \\
4.47 \\
2.40 \\
.14 \\
.36 \\
3.71\end{array}$ \\
\hline
\end{tabular}

1 Determined by difference.

2 Ratio of combined tannin to hide substance.

$34.9 \mathrm{~g}$ of dry leather in $100 \mathrm{ml}$ distilled water.

\section{RESULTS AND DISCUSSION}

The data compiled in this study are presented in Figures 1 to 4 , inclusive. The arrangement is such that the ordinates show the percentage of the original strength of the leather after aging for two years, the amount of sulphuric acid added, and the original $\mathrm{pH}$ value of the leather before aging. The storage conditions, unless otherwise noted on the graphs, were constant at 65 per cent relative humidity and $70^{\circ} \mathrm{F}$., in a room illuminated solely by electricity. Each point on the $\mathrm{pH}$-strength curves represents the average of strength determinations on six specimens after aging compared with the average strength of six specimens cut from the same sample before aging. The points in some cases scatter badly until an apparent critical position is reached after which the downward trend, representing loss of strength, is clearly defined. The initial scattering of the points is characteristic of the strength variations of normal leather and emphasizes the advisability of using a large number of samples.

A glance at the $\mathrm{pH}$-strength curves immediately reveals the important fact that each of the 13 leathers begins to show deterioration due to acid at or near $\mathrm{pH} 3$, below which value the deterioration steadily increases. There is a well-defined break in the curves in every case near $\mathrm{pH} 3$. It is important to note that this apparent critical point is common to all of the leathers without relation to the kind of tanning material used, the aging conditions, the amount of acid added to the leather, originally, the initial $\mathrm{pH}$ of the leather, or the degree of tannage. The extent of the variation of these factors may be observed readily on the graphs. It is of particular interest

10 E. L. Wallace and John Beek, jr., A Comparison of the Quinhydrone and Hydrogen Electrodes in Solutions Containing Tannin, B. S. Jour. Research, vol. 4 (RP176), p. 737, 1930. 
to note the acid added to bring the various leathers to $\mathrm{pH} 3$. This raries from about 0.4 per cent for lot No. 4 to about 1.8 per cent for lot No. 3.

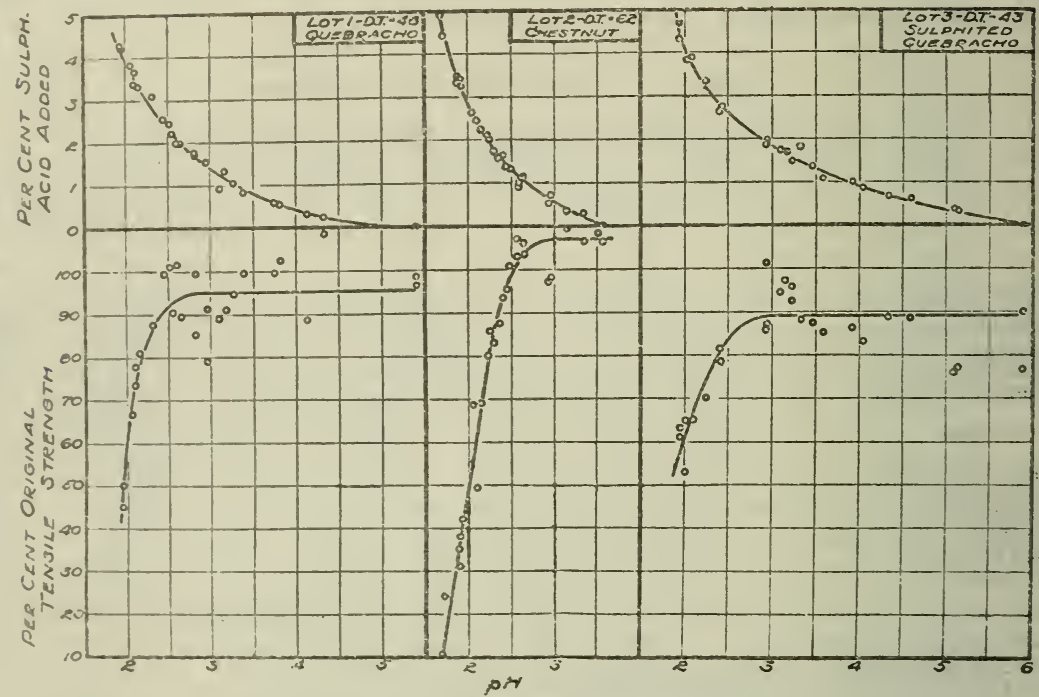

Frgure 1.-Results for lots Nos, 1, 2, and B, showing acid added and loss of strength on aging as a function of $\mathrm{pH}$

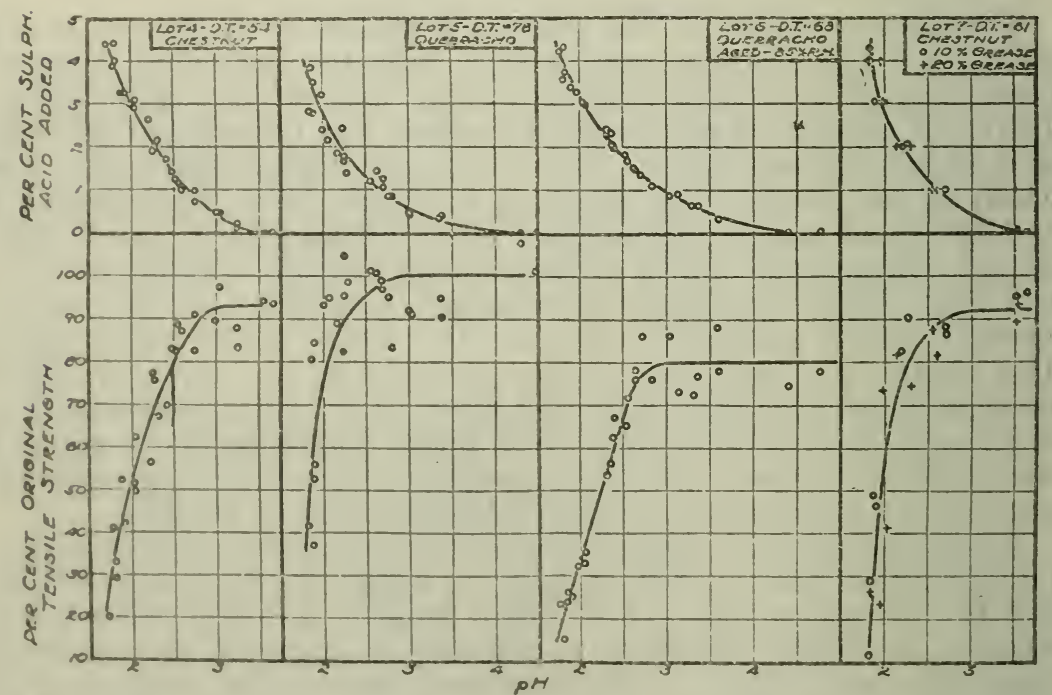

Higune 2.- Results for lots Nos. 4, 5, 6, and 7, showing acid added and loss of strength on aging as a function of $\mathrm{pH}$

Since the pHI at which deterioration starts appears to be independent of the above-mentioned variables it was considered that the critical point might be better located by arernging the results of all the 13 lots. This is done in the last graph of Figure 4 after moving the parts of the curves for zero per cent acid to a uniform base of 100 . 
Here again it is clear that deterioration starts at or near $\mathrm{pH} 3$. This curve may be said to be typical of the shape of a $\mathrm{pH}$-deterioration curve for any vegetable-tanned leather containing sulphuric acid al-

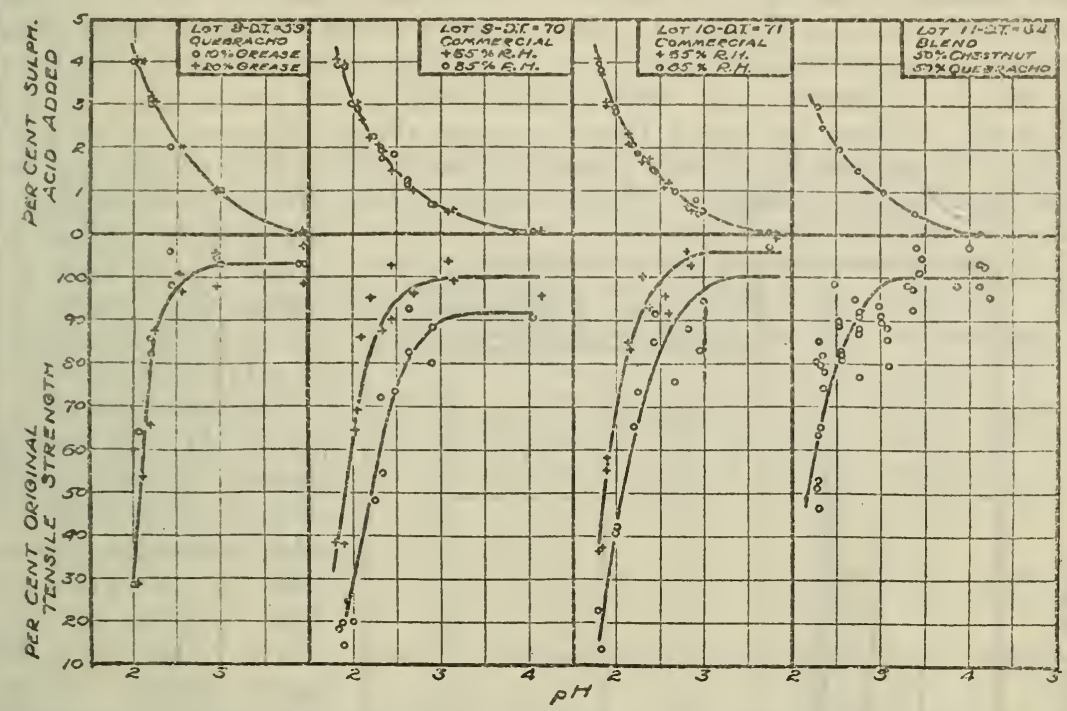

Figure 3.-Results for lots Nos. 8, 9, 10, and 11, showing acid added and loss of strength on aging as a function of $\mathrm{pH}$

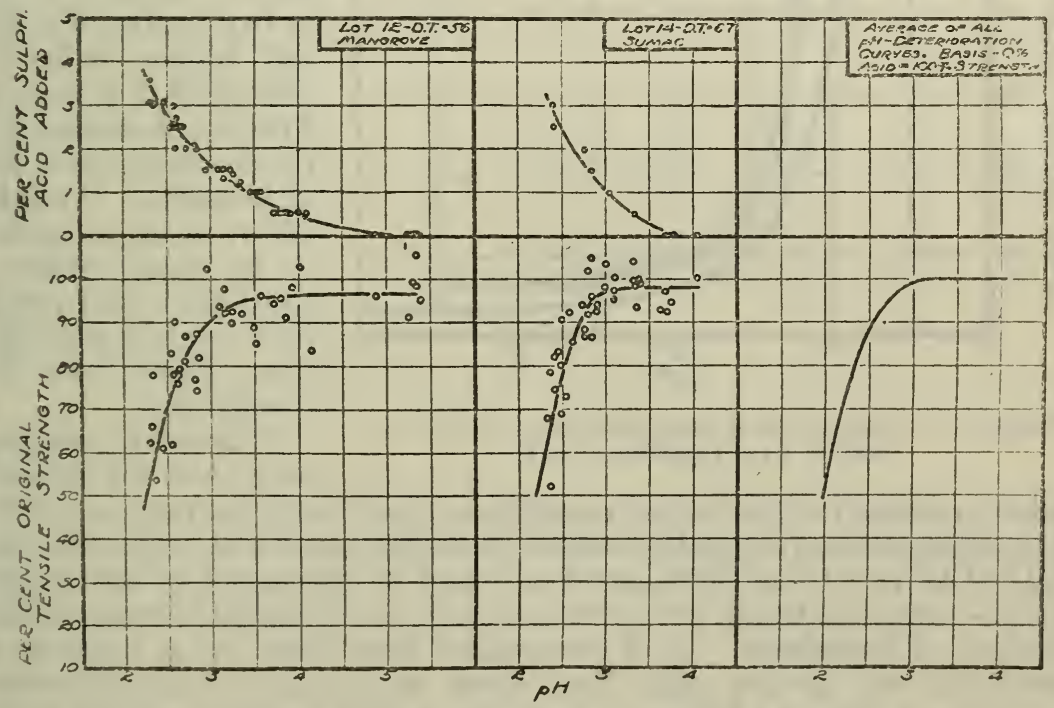

FIGURE 4.-Results for lots Nos. 12 and 14, showing acid added and loss of strength on aging as a function of $p H$. Also average $p H$-strength curve for all lots

though the portion of the curve below pH 3 may vary in its slope due to a difference in the rate of deterioration.

Since deterioration of all the leathers starts at about the same $\mathrm{pH}$, it appears that the hide substance itself exerts the major influence. 
Three of the aged leathers, lot No. 4 (chestnut), lot No. 6 (quebracho), and lot No. 9 (commercial), were examined for extractable nitrogen. Twenty-gram samples were extracted with $200 \mathrm{ml}$ of distilled water in a shake-bottle for four hours at room temperature. The solution was filtered and a Kjeldahl determination made on an aliquot. The results are presented in Figure 5 as a function of the $\mathrm{pH}$ of the leathers. It will be observed that very little nitrogen was extractable at the high $\mathrm{pH}$ values, but that there was an abrupt increase at or near pH 3. These results closely parallel those obtained by measuring the loss in strength on aging. Thus it appears that the hide substance in

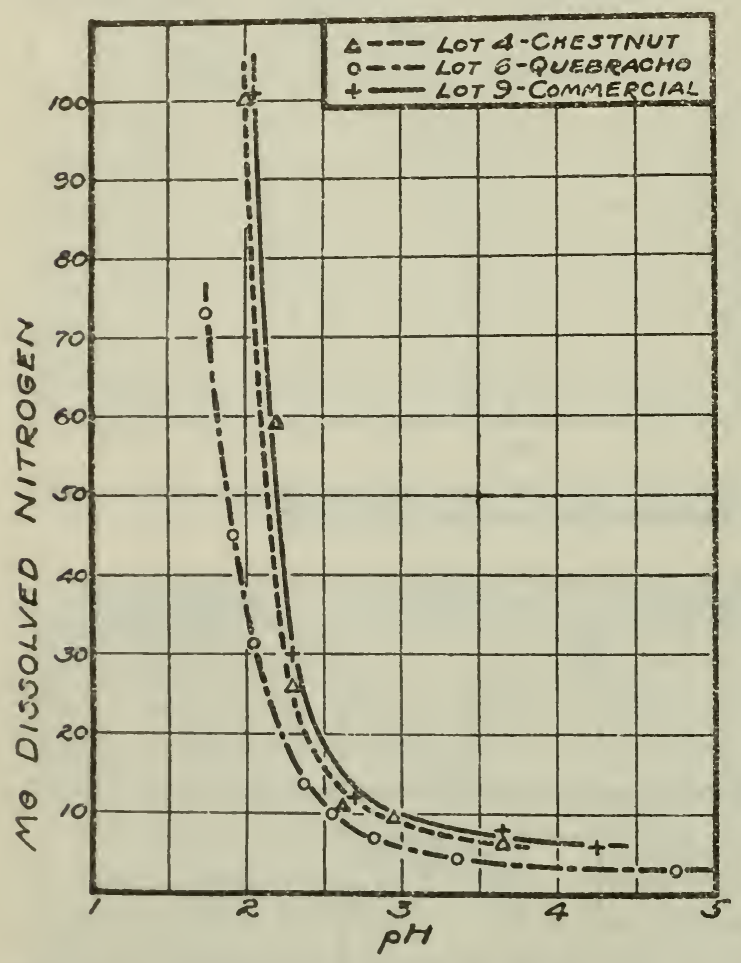

Figore 5.-Hydrolysis of aged leathers, lots Nos. 4, 6, and 9 , as a function of $p H$

the leather begins to break down and deterioration starts at about $\mathrm{pH} 3$ regardless of other factors.

The selection of the exact $\mathrm{pH}$ at which serious deterioration of these leathers started is naturally a question of judgment. The results of this work make $\mathrm{pH} 3$ the most logical choice atlhough it is conceivable that the actual value might be oneor two-tenths of a $\mathrm{pH}$ unit higher or lower. Certainly it is near 3 . This is not necessarily the limiting value for all leathers. It might be lower for a leather to be used within a short time and possibly higher for a leather from which long life is expected.

It is well to mention here that the information presented in this report constitutes specifically the results of twoyear aging tests on vegetable tanned-leathers treated with sulphuric acid. All but two of the leathers, lots Nos. 9 and 10, representing commercial rough-tanned material, were prepared in the experimental tannery at the Bureau of Standards. It is recognized that there are a number of materials and factors other than those studied in this investigation which may have an influence upon the $\mathrm{pH}$ of leather and the value of such a measurement for indicating harmful acidity. In this connection we now have in progress aging tests on typical leathers to determine the effect of sulphuric acid when sulphite cellulose extracts, synthetic tanning materials, sulphonated oils, glucose, and Epsom salts are also present. Typical leathers containing oxalic acid are also being studied. The results obtrined thus far in a study of the 
basic materials used in making leather substantiate the inference of Kohn and Crede that the minimum $\mathrm{pH}$ of good leather must be around 3 , and appear to justify serious consideration of a $\mathrm{pH}$ measurement as a more reliable indication of harmful acidity in leather than any direct method now any use.

\section{SUMMARY}

It is shown that pure vegetable-tanned leathers treated with sulphuric acid and aged for two years start to deteriorate at or near $\mathrm{pH}$ 3 . This was found to be true for 13 different leathers regardless of the kind of vegetable tanning material used, the degree of tannage, the amount of sulphuric acid added to the leather originally, the aging conditions, and the $\mathrm{pH}$ of the original leather before being treated with acid. Thus the potential value of a $\mathrm{pH}$ measurement for evaluating leather with respect to harmful acidity is indicated. Serious consideration of its use is advocated with limiting values for different leather's to be governed by the length of service expected and the conditions of use.

Washington, February 13, 1933. 